\title{
Dispersion of Elongated Gold Nanoparticles Aligned in a Pseudoboehmite Matrix by Sol-Gel Method
}

\author{
Hiromitsu KOZUKA, Masahiro OKUNO and Toshinobu YOKO \\ Institute for Chemical Research, Kyoto University, Uji-shi, Kyoto 611 \\ ゾル-ゲル法による擬ベーマイトマトリックスヘの長球金ナノ粒子の配向分散 \\ 幸塚広光・奥野正裕・横尾俊信 \\ 京都大学化学研究所, 611 京都府宇治市五ヶ庄
}

[Received July 26, 1995; Accepted November 13, 1995]

\begin{abstract}
Pseudoboehmite coating films containing dispersed gold nanoparticles were prepared by sol-gel method. A pseudoboehmite sol was prepared by refluxing a mixture of aluminum tri-sec-butoxide and hydrochloric acid, and then tetrachloroauric acid tetrahydrate was dissolved in the resultant sol. Gel films were deposited on slide glass substrates by spin-coating, dried at $120^{\circ} \mathrm{C}$, and exposed to hydrazine vapor at room temperature in order to precipitate gold particles in the films. Transmission electron microscopic observation of the coating films revealed precipitation of aligned, elongated gold nanoparticles of aspect ratios of 2-4. The optical absorption due to surface plasma resonance of gold particles, however, did not show any dependence on the direction of polarization, implying that the elongated gold particles are aligned only in a microscopic region.
\end{abstract}

Key-words : Nanoparticle, Nanocomposite, Prolate spheroid, Gold metal particles, Surface plasma resonance, Thin films, Sol-gel method, Polarizer

\section{Introduction}

Nanocomposites composed of ultrafine particles and oxide matrices have been attracting much attention as advanced materials of various functions. Surface plasma resonance (SPR) of metal particles, which enhances the oscillating electric field inside and outside nearby the particles, is the source of optical effects such as enhanced fluorescence of dye molecules and rare earth ions, ${ }^{1)-4)}$ enhanced Raman scattering from molecules (SERS), 5) and enhanced optical third order nonlinearity.6)-9) Modification of electrochromic properties of $\mathrm{WO}_{3}{ }^{10)}$ and $\mathrm{V}_{2} \mathrm{O}_{5}{ }^{11)}$ has also been carried out by doping them with fine metal particles. Nanocomposite coating films with selective optical absorption and reflection properties are now commercially available. ${ }^{12)}$ Improvement of the mechanical properties of ceramic materials by introducing metal nanoparticles is another subject of significance. ${ }^{13)}$

What is demanded for preparing materials of SPRinduced advanced optical functions are to control the size and shape of the metal particles and to disperse metal particles in high volume fraction; the former determines the wavelength of SPR and the latter provides intense SPR. Another challenging task is to disperse elongated metal particles aligned in dielectric matrices. Metal particles of elongated shape exhibit anisotropic SPR, i.e., SPR that depends on the direction of oscillating electric field with respect to the particle geometry.5) Therefore, composite materials dispersed with aligned, elongated metal particles have different SPR wavelengths with different directions of the oscillating electric field. Corning Glass Works Co. have already commercialized an oxide glass polarizer containing aligned, elongated silver metal particles, which can be used as optical isolator device. ${ }^{14)-18)}$ They prepared these materials by stretching the melt-quenched glass containing silver particles around its softening temperature. The content and aspect ratio of the silver particles in glass are about $10^{-3}$ mass $\%$ and $1.0-2.7$, respectively, with a broad size distribution.

The present authors have already shown that oxide materials containing fine metal particles with a variety of sizes and shapes in several vol\% can be prepared by sol-gel method. ${ }^{19)-25)}$ Our basic idea is that it is possible to precipitate metal particles in the porous gel matrices without the undesired segregation of large metal particles owing to the limited space for particle growth, and at the same time to control the size and shape of the metal particles through changing the microstructure and properties of the gel matrix..$^{19)-21), 24)}$ On the basis of the above idea, composites containing aligned, elongated metal particles can be prepared by sol-gel method if gel matrices have a unidirectionally aligned texture. In addition, high volume fraction of aligned, elongated particles would provide thin films with anisotropic optical absorption.

In the present work, we attempted to prepare fibrous pseudoboehmite sols from aluminum tri-secbutoxide, to align the pseudoboehmite particles on a substrate by spin-coating, and to precipitate gold particles along the aligned texture of pseudoboehmite matrices. The fibrous pseudoboehmite sol particles are expected to align radially on the substrate by 
shear stress that emerges along the direction of the centrifugal force.

\section{Experimental}

$\mathrm{Al}\left(\mathrm{OC}_{4} \mathrm{H}_{9}{ }^{\text {sec }}\right)_{3}$ (Kanto Chemical Co., Inc.), 36\% $\mathrm{HCl}$ aq. (Wako Pure Chemical Ind. Ltd.) and distilled water were mixed together at room temperature and refluxed at $84^{\circ} \mathrm{C}$ for 6 or $7 \mathrm{~h}$ to form a pseudoboehmite sol. After cooling the sol to room temperature, $\mathrm{HAuCl}_{4} \cdot 4 \mathrm{H}_{2} \mathrm{O}$ (Nacalai Tesque, Inc.) was dissolved in the sol. The molar ratio, $\mathrm{Al}\left(\mathrm{OC}_{4} \mathrm{H}_{9}{ }^{\mathrm{sec}}\right)_{3}$ : $\mathrm{H}_{2} \mathrm{O}: \mathrm{HCl}: \mathrm{HAuCl}_{4} \cdot 4 \mathrm{H}_{2} \mathrm{O}$, was adjusted to $1: 100$ : $0.05: 0.0253$. A gel film was deposited on a slide glass substrate using the sol as the coating solution by spin-coating at $3400 \mathrm{rpm}$. The gel film was dried at $120^{\circ} \mathrm{C}$ for $10 \mathrm{~min}$ and then placed over a $5 \%$ $\mathrm{NH}_{2} \mathrm{NH}_{2} \cdot \mathrm{H}_{2} \mathrm{O}$ (Nacalai Tesque, Inc.) ethanolic solution at room temperature.

$\mathrm{X}$-ray diffraction (XRD) analysis of the films was made by means of an X-ray diffractometer (Rigaku $\mathrm{RAD}$ IIA) with $\mathrm{Cu} \mathrm{K} \alpha$ radiation. The microstructure of the films was observed by a transmission electron microscope (TEM : Hitachi Ltd., HU-11D). The optical absorption spectra were measured with a UV-visible spectrophotometer (Hitachi Ltd., U3500) using a slide glass substrate as the reference. The thickness of the films was measured with a surface profilometer (Kosaka Laboratory Co., SE30D).

\section{Results and discussion}

Coating films of $20-25 \mathrm{~nm}$ in thickness were obtained. Figure 1 shows the XRD pattern of the film sample prepared from the sol refluxed for $7 \mathrm{~h}$ along with that of the dried gel powders obtained by concentrating, gelling and drying the same sol at $120^{\circ} \mathrm{C}$. The XRD pattern of the dried gel powder clearly shows the peaks attributed to boehmite $\gamma$-A1OOH. The $\gamma$-A1OOH (020) peak was observed at $2 \theta$ $=13.2^{\circ}$, from which the $(020)$ spacing is calculated to be $0.67 \mathrm{~nm}$. This spacing is much larger than that calculated for an ideally ordered $\gamma$-AlOOH lattice $(0.61 \mathrm{~nm})$, indicating that interlayer water exists in the structure and the phase is pseudoboehmite. Only $\gamma$-AlOOH (020) peak was observed at $2 \theta=13.2^{\circ}$ in the pattern of the film sample, revealing the preferred orientation of $\gamma$-AlOOH (020) plane.

The TEM pictures of the film samples (Fig. 2) clearly indicate that elongated gold nanoparticles of aspect ratios of 2-4 are aligned along the fibrous pseudoboehmite matrix. Because of the elongated shape of the gold particles, the optical absorption due to SPR of gold was observed at a long wavelength of about $660 \mathrm{~nm}$ (Fig. 3, curve a). It should be pointed out that the gold particle size is of the order of the film thickness.

Such an anisotropic texture was not observed when a larger amount of hydrochloric acid was introduced in the starting solution or when the gel film

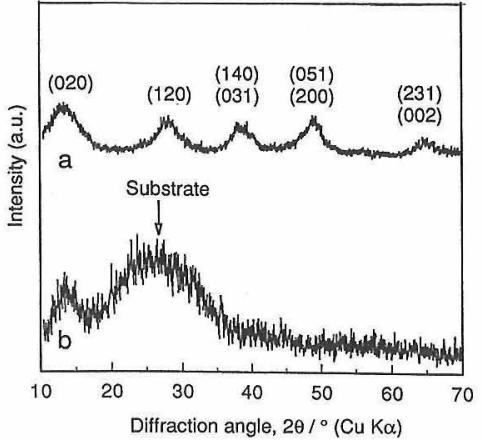

Fig. 1. XRD pattern of the dried gel powder (a) and coating film (b) that were prepared from a sol of $\mathrm{HCl} / \mathrm{Al}\left(\mathrm{OC}_{4} \mathrm{H}_{9}{ }^{s e c}\right)_{3}=0.05$ refluxed for $7 \mathrm{~h}$. The powder sample was obtained by concentrating, gelling and drying the sol at $120^{\circ} \mathrm{C}$ for $12 \mathrm{~h}$. The film sample was exposed to the hydrazine vapor for $10 \mathrm{~min}$ after drying at $120^{\circ} \mathrm{C}$ for $10 \mathrm{~min}$. Miller indices denoted in the figure are those of boehmite $\gamma$-AlOOH.

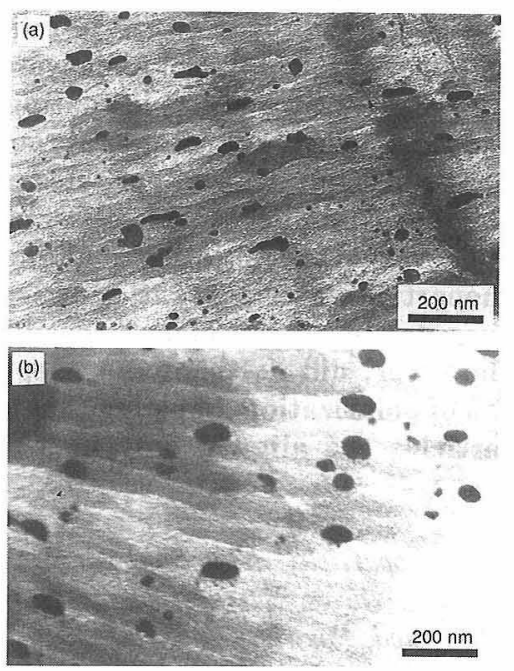

Fig. 2. TEM pictures of the coating films prepared from a sol of $\mathrm{HCl} / \mathrm{Al}\left(\mathrm{OC}_{4} \mathrm{H}_{9}{ }^{\text {sec }}\right)_{3}=0.05$ and exposed to the hydrazine vapor. (a) the refluxing time : $6 \mathrm{~h}$, the reducing time $: 10 \mathrm{~s}$. (b) the refluxing time : $7 \mathrm{~h}$, the reducing time $: 10 \mathrm{~min}$.

was exposed to hydrazine vapor without drying. Figure 4 shows the TEM picture of the film sample prepared from a solution of $\mathrm{HCl} / \mathrm{Al}\left(\mathrm{OC}_{4} \mathrm{H}_{9}{ }^{\text {sec }}\right)_{3}=0.5$, where spherical gold particles less than $20 \mathrm{~nm}$ in size are seen. A much smaller amount of elongated particles are also seen, although they are not aligned in a common direction. It should be noted that the matrix does not show any distinct, aligned texture, which results from the peptization of pseudoboehmite particles. Figure 5 shows the TEM picture of the film sample prepared by exposing the gel film to hydrazine vapor prior to drying. Round-shaped gold particles less than $20 \mathrm{~nm}$ in size are dispersed in the pseudoboehmite matrix of aligned texture. Dispersion of spherical, small gold particles is also reflected in the optical absorption spectra (Fig. 3, curve b), which showed a peak at a shorter wavelength of $600 \mathrm{~nm}$.

It can be concluded from the above observations that the aligned texture of the matrix and the drying 


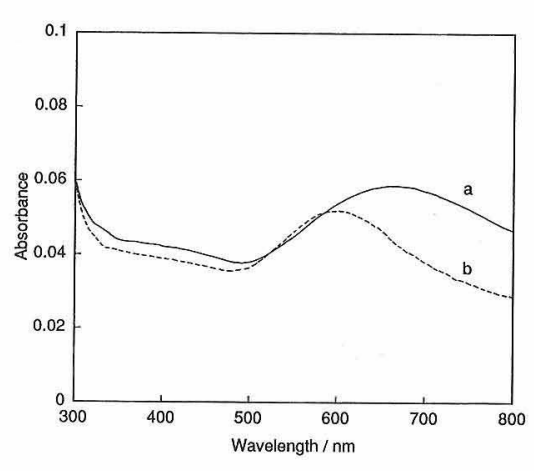

Fig. 3

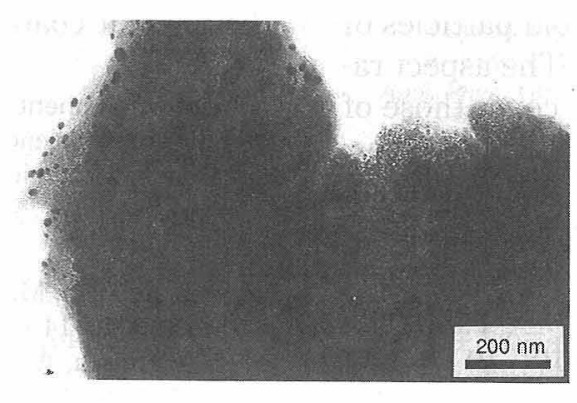

Fig. 4

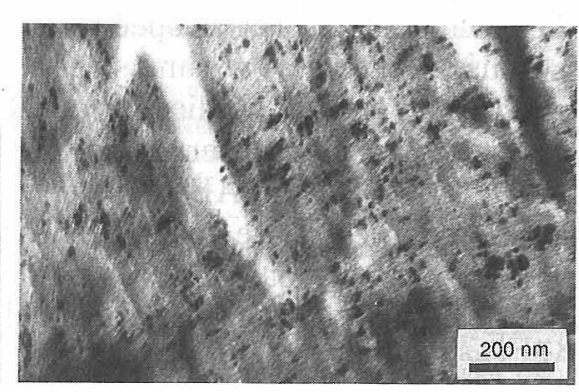

Fig. 5

Fig. 3. Optical absorption spectra of the coating films that were prepared from a sol of $\mathrm{HCl} / \mathrm{Al}\left(\mathrm{OC}_{4} \mathrm{H}^{\mathrm{sec}}\right)_{3}=0.05$ refluxed for $6 \mathrm{~h}$. Curve $\mathrm{a}$ : the film dried at $120^{\circ} \mathrm{C}$ prior to exposing to the hydrazine vapor for $10 \mathrm{~min}$. Curve $\mathrm{b}:$ the film exposed to the hydrazine vapor for $10 \mathrm{~min}$ prior to drying at $120^{\circ} \mathrm{C}$.

Fig. 4. TEM picture of the coating film that was prepared from a sol of $\mathrm{HCl} / \mathrm{Al}\left(\mathrm{OC}_{4} \mathrm{H}_{9}{ }^{\mathrm{sec}}\right)_{3}=0.5$ refluxed for $6 \mathrm{~h}$, and was dried at $120^{\circ} \mathrm{C}$ and exposed to the hydrazine vapor for $10 \mathrm{~min}$.

Fig. 5. TEM picture of the coating film that was prepared from a sol of $\mathrm{HCl} / \mathrm{Al}\left(\mathrm{OC}_{4} \mathrm{H}_{9}{ }^{\mathrm{sec}}\right)_{3}=0.05$ refluxed for $6 \mathrm{~h}$ and was exposed to the hydrazine vapor for $10 \mathrm{~min}$ prior to drying at $120^{\circ} \mathrm{C}$.

of the gel film prior to the reduction are necessary for precipitation of aligned, elongated gold particles. During the drying process $\mathrm{AuCl}_{4}{ }^{-}$ions are probably concentrated in regions between the fibrous pseudoboehmite sol particles, followed by the formation of elongated gold particles via reduction.

Optical absorption spectra were measured for a limited area $(1 \mathrm{~mm} \phi)$ of the films using a polarized incident light. Although aligned, elongated gold particles were observed in the TEM image, the absorption spectra of the films had no dependence on the polarization direction. The distribution in aspect ratio and size of the gold particles and the coexistence of smaller, spherical particles are possible causes of the absence of the polarization direction dependence of the optical absorption. In order to check the effects of aspect ratio and size of the gold particles on optical absorption spectra, theoretical computation of absorption spectra was carried out for prolate gold particles embedded in a matrix of a refractive index 1.5 as described below.

Optical absorption coefficient $\alpha$ of metal particles dispersed in a dielectric matrix is expressed by the following equation ${ }^{15)}$ based on Mie theory; ${ }^{26)}$

$$
\alpha=\frac{2 \pi p \varepsilon_{\mathrm{d}}^{3 / 2}}{A^{2} \lambda} \frac{\varepsilon_{\mathrm{m}}^{\prime \prime}}{\left(\varepsilon_{\mathrm{m}}^{\prime}+\varepsilon_{\mathrm{d}}(1 / A-1)\right)^{2}+\varepsilon_{\mathrm{m}}^{\prime \prime 2}}
$$

where $\varepsilon_{\mathrm{m}}=\dot{\varepsilon}_{\mathrm{m}}^{\prime}+i \varepsilon_{\mathrm{m}}^{\prime \prime}$ is the dielectric function of metal particles, $\varepsilon_{\mathrm{d}}$ the dielectric constant of the matrix, $A$ the depolarization factor, $p$ the volume fraction of metal particles and $\lambda$ the wavelength of light. $\varepsilon_{\mathrm{m}}^{\prime}, \varepsilon_{\mathrm{m}}^{\prime \prime}$, and $\varepsilon_{\mathrm{d}}$ are, of course, functions of wavelength $\lambda$. In order to take account of the effect of metal particle size, effective depolarization factor $A_{\text {eff }}$ by Wokaun ${ }^{5)}$ was employed as $A$ in Eq. (1);

$$
\begin{aligned}
& A_{\text {eff }}=A_{\text {stat }}-\frac{1}{3} q^{2}-\frac{1}{24} q^{4}-\ldots \ldots \ldots . . \\
& q=k\left(a^{2} c\right)^{1 / 3}
\end{aligned}
$$

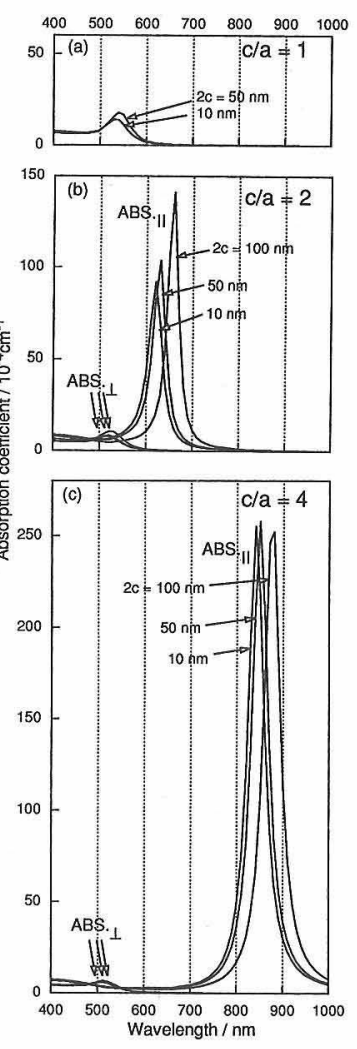

Fig. 6. Calculated optical absorption curves for gold particles of various aspect ratios $c / a$ and sizes $2 c$ dispersed in a matrix of refractive index 1.5. The aspect ratio $c / a$ is (a) 1 , (b) 2 and (c) 4 . $\mathrm{ABS}_{\|}$and $\mathrm{ABS}_{._{\perp}}$ refer to the optical absorption due to the oscillating electrical field the direction of which is parallel and perpendicular to the major axis of the prolate gold particles, respectively.

where $a$ and $c$ are the lengths of the minor and major half axes of the prolate spheroid particles, respectively, and $k=2 \pi / \lambda$. Static depolarization factor $A_{\text {stat }}$ is determined only by the aspect ratio of the prolate spheroid particles and the direction of polarization. ${ }^{27)}$ In calculation $\varepsilon_{\mathrm{m}}^{\prime}$ and $\varepsilon_{\mathrm{m}}^{\prime \prime}$ data were taken 
from Johnson and Christy's paper. ${ }^{28)}$ Figure 6 shows the calculated absorption spectra of gold particles of various aspect ratios $c / a$ and sizes $2 c$. The aspect ratios $c / a$ and sizes $2 c$ studied here well cover those of the gold particles observed in the TEM images.

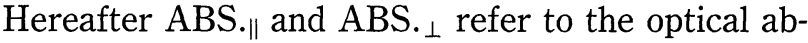
sorption of the prolate gold particles whose symmetry axis, namely, major axis is parallel and perpendicular to the oscillating electrical field, respectively.

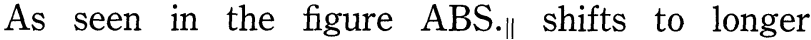
wavelengths with increasing aspect ratio, whereas ABS. $\perp$ unchanged in wavelength and much smaller in intensity. The size effect is also seen in the figure, where ABS. .| shifts to longer wavelengths with increasing particle size. The peak position of $\mathrm{ABS}_{{ }_{\perp}}$ is, however, fixed at about $520 \mathrm{~nm}$ even when the particle size increases. This clearly suggests that even if the aligned gold particles have distribution in aspect

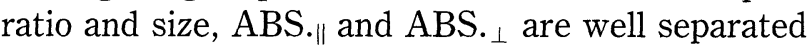
in wavelength. In other words, the material should exhibit dependence of optical absorption on the polarization direction in wavelengths longer than $600 \mathrm{~nm}$ as far as the prolate gold particles are aligned in a particular direction.

The present film samples, however, did not show such a dependence of the absorption on the polarization direction. It is therefore considered that the elongated gold particles precipitated are aligned not in a macroscopic scale but in a microscopic region. The fibrous pseudoboehmite sol particles may be aligned only in a microscopic region and not be aligned radially on the substrate, although their radial alignment by shear stress was initially intended. In order to obtain an anisotropic texture in a macroscopic scale, the dispersion state of the sol particles and the flow characteristics of the sol should be much more carefully controlled.

\section{Conclusion}

Elongated gold nanoparticles could be precipitated and aligned along the microscopically oriented fibrous pseudoboehmite films by sol-gel method using aluminum tri-sec-butoxide and tetrachloroauric acid tetrahydrate as the starting materials and hydrazine monohydrate as the reducing agent. It was found that the aligned texture of the matrix and the drying of the gel film prior to exposure to the hydrazine vapor are needed for the achievement of the anisotropic dispersion of gold particles. The optical absorption due to surface plasma resonance of gold particles, however, did not show dependence on the direction of polarization. Based on the computed optical absorption, the elongated gold particles were con- sidered to be aligned only in a microscopic region in the present coating films.

Acknowledgment $\mathrm{H}$. Kozuka thanks the Japanese Ministry of Education, Science and Culture for the financial support by Grant-in-Aid for Scientific Research (No. 06650965).

\section{References}

1) R. Reisfeld, M. Eyal and D. Brusilovsky, Chem. Phys. Lett., 153, 210-14 (1988).

2) A. Hinsch, A. Zastrow and V. Witter, Solar Energy Mater. 21, 151-64 (1990).

3) H. R. Wilson, Solar Energy Mater., 16, 223-34 (1987).

4) O. L. Malta and M. A. Couto dos Santos, Chem. Phys. Lett., 174, 13-18 (1990).

5) A. Wokaun, Mol. Phys., 56, 1-33 (1985).

6) F. Hache, D. Ricard, C. Flytzanis and U. Kreibig, Appl. Phys. A, 47, 347-57 (1988).

7) K. Fukumi, A. Chayahara, K. Kadono, T. Sakaguchi, Y. Horino, M. Miya, K. Fujii, J. Hayakawa and M. Satou, J. Appl. Phys., 75, 3075-80 (1994).

8) J. Matsuoka, R. Mizutani, S. Kaneko, H. Nasu, K. Kamiya, K. Kadono, T. Sakaguchi and M. Miya, J. Ceram. Soc. Japan., 101, 53-58 (1993).

9) T. Kineri, M. Mori, K. Kadono, T. Sakaguchi, M. Miya, H. Wakabayashi and T. Tsuchiya, J. Ceram. Soc. Japan., 101, 1340-45 (1993).

10) E. K. Sichel, J. I. Gittleman and J. Zelez, Appl. Phys. Lett., 31, 109-11 (1977).

11) K. Nagase, Y. Shimizu, N. Miura and N. Yamazoe, J. Ceram. Soc. Japan., 102, 571-77 (1994).

12) H. Dislich, "Sol-Gel Technology for Thin Films, Fibers, Preforms, Electronics and Specialty Shapes”, Ed. by L. C. Klein, Noyes Publications, Park Ridge (1988) pp. 50-79.

13) K. Niihara, T. Sekino and A. Nakahira, "New Functionality Materials, Vol. C”, Ed. by T. Tsuruta, M. Doyama and M. Seno, Elsevier Sci. Publ. B. V., N. Y. (1993) pp. 751-56.

14) S. D. Stookey and R. J. Araujo, Appl. Opt., 7, 777-79 (1968).

15) T. P. Seward, III , J. Non-Cryst. Solids, 40, 499-513 (1980)

16) D. N. Gritz, SPIE, 750, 18-26 (1987).

17) T. P. Seward, III, SPIE, 464, 96-103 (1984)

18) N. F. Borrelli and C. L. Davis, SPIE, 1746, 336-42 (1992).

19) H. Kozuka and S. Sakka, Chem. Mater., 5, 222-28 (1993).

20) H. Kozuka, G. Zhao and S. Sakka, J. Sol-Gel Sci. Technol., 2, 741-44 (1994).

21) P. Innocenzi, H. Kozuka and S. Sakka, J. Sol-Gel Sci. Technol., 1, 305-18 (1994).

22) H. Kozuka, G. Zhao and S. Sakka, Bull. Inst. Chem. Res. Kyoto Univ., 72, 209-24 (1994).

23) P. Innocenzi and H. Kozuka, J. Sol-Gel Sci. Technol., 3, 229 33 (1994).

24) S. Sakka, H. Kozuka and G. Zhao, SPIE, 2288, 108-19 (1994).

25) G. Zhao, H. Kozuka and S. Sakka, J. Sol-Gel Sci. Technol., 4, 37-47 (1995).

26) G. C. Papavassiliou, Prog. Solid State Chem., 12, 185-271 (1979).

27) J. A. Osborn, Phys. Rev., 67, 351-57 (1945).

28) P. B. Johnson and R. W. Christy, Phys. Rev. B, 6, 4370-79 (1972). 